\title{
GÊNERO E JORNADA DE TRABALHO: ANÁLISE DAS RELAÇÕES ENTRE MERCADO DE TRABALHO E FAMÍLIA
}

\author{
GENDER AND THE WORK WEEK: ANALYSIS OF THE RELATIONSHIPS BETWEEN THE WORK \\ MARKET AND THE FAMILY
}

\author{
Claudio Salvadori Dedecca ${ }^{1}$ \\ Camila Santos Matos de Freitas Ribeiro ${ }^{2}$ \\ Fernando Hajime Ishii ${ }^{3}$
}

Resumo A Pesquisa Nacional por Amostra de Domicílios (Pnad) propicia, desde o início da década, informações sobre a existência e a extensão do trabalho em afazeres domésticos. Esta informação, acrescida da jornada no mercado de trabalho, possibilita a construção de um indicador sobre a intensidade da jornada total de trabalho no mercado e extramercado. Este ensaio analisa a intensidade da jornada total de trabalho para homens e mulheres, considerando as condições de inserção ocupacional, o rendimento familiar e o ciclo familiar. A análise explicita que mulheres em ocupações menos estáveis, de menor qualificação, maior renda e com filhos mais jovens tendem a ter jornadas totais mais longas quando comparadas às dos homens em situação ocupacional e familiar semelhante e às das mulheres com ocupações mais qualificadas, de mais alta renda e também com filhos jovens. Os resultados do ensaio indicam a necessidade de políticas públicas capazes de construir instrumentos de proteção às mulheres e que considerem a diferenciação social relacionada ao tipo de inserção no mercado. Ademais, o estudo aponta que as políticas de emprego não podem ficar restritas ao mercado de trabalho, necessitando também alcançar as condições de organização do núcleo familiar.

Palavras-chave tempo de trabalho; gênero; ocupação; mercado de trabalho; desigualdade.
Abstract the National Survey per Household Sampling (NSHS) has provided, since the early 2000's, information on the existence and extent of work in household chores. This information, added of the work week in the work market, allows for the construction of an index of the intensity of the total work week in the market and in the extra-market. This essay analyzes the intensity of the total work week for men and women, considering the conditions of occupational insertion, family income, and the family cycle. The analysis shows that women who hold less stable occupations that require less qualification, who have better incomes, and have younger children tend to have longer total work weeks compared to that of men in similar occupational and family conditions and also to women who hold more qualified, higher income positions and also have young children. The results of the assay indicate the need for public policies that are capable of building instruments to protect women and that consider the social differentiation related to the type of insertion in the market. Furthermore, the study shows that job policies cannot be restricted to the work market. It is also necessary to reach the family nucleus organization conditions.

Keywords time of work; gender; occupation; work market; inequality. 


\begin{abstract}
A palaura 'tempos' é o símbolo de uma relação que um grupo humano (isto é, um grupo de seres vivos com a faculdade biológica de se pôr em acordo e sintetizar) estabelece entre dois ou mais processos, dentre os quais tomam um como quadro de referência ou medida dos demais. (Norbert Elias, Sobre el Tiempo)
\end{abstract}

\section{Introdução}

Este ensaio explora a desigualdade entre homens e mulheres estabelecida na relação entre as jornadas de trabalho para o mercado e para a reprodução social e a inserção ocupacional no mercado de trabalho. O estudo procura analisar a relação entre status ocupacional, renda e jornada total de trabalho com o objetivo de identificar os elementos relevantes para a discriminação entre homens e mulheres, seja no mercado de trabalho, seja no âmbito familiar.

Ele está organizado em três partes. Na primeira, encontra-se uma síntese sobre o debate atual acerca do tempo de trabalho na sociedade capitalista e os desafios que esta discussão coloca para as políticas públicas e ações orientadas para uma maior igualdade entre sexos. Na segunda, são exploradas as dimensões mais relevantes da diferenciação entre homens e mulheres em termos de jornadas de trabalho tanto no mercado como na família e sua relação com o mercado de trabalho. Finalmente, é apresentado um arrazoado dos principais achados propiciados pelo estudo.

\section{Sobre os tempos de trabalho}

É cada vez mais ampla a perspectiva adotada pelas instituições nacionais e internacionais sobre a análise do tempo de trabalho. O motivo da preocupação decorre da necessidade de se tratar de tempos e não mais de tempo de trabalho. Mudanças econômicas e sociais, em curso desde os anos 70, vêm tornando progressivamente mais complexas as formas de atividade produtiva realizadas pela população adulta, bem como as relações que elas estabelecem entre si. Como toda atividade ocupa tempo das pessoas, é impossível analisar as transformações que sobre ela recaem sem compreender suas implicações para o tempo que elas consomem na vida dos indivíduos (Elias, 1989; Adam, 1990). 
A complexidade destas transformações e seus impactos sobre a organização do trabalho não podem ser considerados novos na trajetória do desenvolvimento capitalista mais geral. De fato, esta complexidade tem raiz na Segunda Revolução Industrial (1860-1890), quando as novas condições estabelecidas para o progresso técnico e a difusão da energia elétrica revolucionaram a relação entre homens e máquinas, ampliando significativamente a subordinação humana à tecnologia (Thompson, 1967).

Contudo, o mundo produtivo predominante no século XX apresentava certas características que favoreceram o amplo desenvolvimento da regulação social sobre o contrato e as relações de trabalho. Algumas destas características merecem destaque, pois elas foram decisivas para viabilizar a definição de normas e regras de regulação social, com implicações sobre o uso do tempo de trabalho.

A primeira delas foi a ampliação sistemática do trabalho assalariado como forma privilegiada de contratação de trabalho. A predominância dessa forma de contrato de trabalho abriu uma ampla possibilidade de construção do ator coletivo e político conhecido como sindicato, criando a perspectiva de os trabalhadores passarem a influenciar sobre as condições e a organização do trabalho nas empresas.

Outras características da organização produtiva foram também importantes, pois favoreceram a construção da organização coletiva do trabalho pelos assalariados. Uma que deve ser apontada é a consolidação de coletivos vinculados a locais específicos e fixos de trabalho. As fábricas, os bancos e mesmo as estradas de ferro constituíram coletivos de trabalhadores a eles vinculados de modo recorrente, bem como organizaram estes coletivos em locais específicos para a realização do trabalho. Era viabilizada a recorrência do trabalho e do local em que ele era exercido. Quem contratava era o proprietário do local, que também determinava o processo de produção e organizava o trabalho. Portanto, mesmo que as sociedades anônimas tenham despersonalizado a figura do capitalista, elas não produziram a despersonalização da empresa.

A outra característica foi a existência de uma rotina cotidiana claramente estabelecida para a maioria dos trabalhadores entre a casa e o local de trabalho, seja em termos de destino como de horários em que faziam o trajeto entre os espaços de consumo e de produção. A maioria dos trabalhadores ia e voltava das fábricas, dos bancos e das lojas em horários e destinos regulares (Thompson, 1967). A grande corporação empresarial apresentava razoável rigidez de sua organização do trabalho.

Uma implicação destas condições de organização da atividade econômica sobre o contrato foi a ampla visibilidade que elas tenderam a dar à jornada de trabalho, em especial sobre sua elevada extensão. Ao longo da segunda metade do século XIX, quando as grandes corporações se consolidaram e 
construíram coletivos de trabalho organizados a partir de uma jornada que consumia parte predominante do tempo diário da população adulta, emergiram grandes movimentos de massa nas economias desenvolvidas da época reivindicando a redução dessa jornada.

Frente à impossibilidade de acordar com as empresas a redução da jornada, em razão da situação de incipiência da organização sindical e especialmente da negociação coletiva, os trabalhadores recorreram ao Estado para que ele conduzisse o processo. ${ }^{4}$ Assim, a regulação pública da jornada de trabalho aparece precocemente como instrumento de intervenção sobre o contrato de trabalho, rompendo a autonomia das partes - empresas e trabalhadores - de estabelecerem os termos em que ela seria exercida (Dedecca, 2005).

\section{A regulação pública da jornada de trabalho}

A importância da regulação pública da jornada de trabalho se expressou na própria constituição da Organização Internacional do Trabalho, em 1919, que teve sua primeira convenção estabelecida no mesmo ano, versando sobre a questão em foco. Tendo a I Conferência Internacional do Trabalho se decidido pela proposição das oito horas diárias e 48 horas semanais de trabalho, a primeira convenção definia orientações para que os países membros adotassem mecanismos de regulação pública da jornada de trabalho. A sua ratificação foi ampla, alcançando rapidamente, inclusive, os países em desenvolvimento.

A relevância desta convenção não pode ser desassociada do padrão de desenvolvimento dominante no capitalismo até os anos 70. Marcado por uma dimensão fortemente nacional, com baixas relações produtivas com os mercados externos, o processo de desenvolvimento centrado no setor industrial favorecia enormemente a regulação pública do contrato e das relações de trabalho. Tendo sua influência fundamentalmente circunscrita ao território das nações, ela tinha capacidade de regular o trabalho dentro das condições de organização local da produção, distribuindo de modo relativamente equilibrado seus efeitos, com baixo risco de provocar maior distorção no processo de concorrência intercapitalista.

As condições políticas mais gerais, propiciadas pela construção dos regimes democráticos, e os efeitos do crescimento, traduzidos em um baixo desemprego no pós-guerra, ampliaram a possibilidade de regulação do contrato e das relações de trabalho nas condições produtivas e técnicas que haviam emergido com a Segunda Revolução Industrial e se difundido ao longo da primeira metade do século XX. 


\section{O fim do crescimento do pós-guerra e a regulação da jornada de trabalho}

Estas condições favoráveis à regulação pública do contrato e das relações de trabalho foram colocadas em xeque a partir do final dos anos 60 . A emergência da crise econômica reduziu a lucratividade das empresas e o crescimento da produção e recolocou o desemprego na ordem do dia das sociedades capitalistas. Estes dois efeitos penalizaram as políticas públicas: de um lado, ao reduzirem o ritmo de crescimento das receitas dos fundos públicos associados às políticas de proteção ao trabalho; e de outro, ao ampliarem os gastos destes fundos públicos com a proteção do desemprego e com a previdência social, em razão do aumento de aposentadorias precoces. A partir dos anos 70, a restrição orçamentária que o Estado começava a viver abria a possibilidade de redução do grau de proteção ao trabalho como forma de controlar os gastos com seguro desemprego e previdência social. 5

Além destas mudanças no cenário econômico e social vivenciadas pelas nações, deve-se considerar a emergência e a expansão rápida do processo de descentralização produtiva realizado pelas empresas como reação à situação de crise, com movimento de subcontratação de produção e serviços tanto no mercado local como no internacional.

As mudanças na organização da produção acabaram por provocar o rompimento da identidade entre empresa, local de produção e local de trabalho. Ademais, elas alimentaram um processo acelerado de externalização pelas empresas de atividades consideradas não vitais para seu desempenho econômico.

Assim, passaram a se proliferar situações ocupacionais onde o trabalhador desconhece a empresa que contrata seu trabalho ou a empresa para a qual seu trabalho se destina. Ademais, ampliou-se a mobilidade espacial do trabalhador, seja porque sua atividade passou a carregar mudanças recorrentes de local para a realização do trabalho, seja porque tais mudanças são determinadas pelo contratante do resultado da sua atividade, que se diferencia do contratante de seu trabalho (Schor, 1991).

Um bom exemplo a ser dado pode ser encontrado na experiência dos grandes supermercados. Estes vendem a área de exposição aos fornecedores, que são responsáveis pela contratação de expositores para alimentar as gôndolas nas plantas. Em geral, os fornecedores selecionam expositores através das empresas de intermediação de mão-de-obra. Assim, o expositor é subordinado a uma empresa que não conhece e trabalha em uma empresa que não o contrata, mas que ele conhece. Ademais, seu turno de trabalho tende a acompanhar a dinâmica da empresa na qual trabalha e não guarda qualquer relação com aquela realizada na empresa que o emprega. 


\section{A nova flexibilidade da jornada de trabalho}

As dissonâncias entre local de trabalho e contrato de trabalho não somente se ampliaram nestes últimos quarenta anos como viabilizaram uma flexibilidade ponderável da jornada de trabalho no interior das empresas. Naquelas em que o local de trabalho, a organização da produção e a contratação de mão-de-obra continuam sendo de sua responsabilidade, observa-se a emergência de acordos individuais ou coletivos sobre a implantação de jornadas flexíveis com a introdução do banco de horas.

As mudanças vêm rompendo a rotina de trabalho em termos de horário e local de atividade. A conhecida semana inglesa, caracterizada por jornada de oito horas durante cinco dias na semana, tem perdido representatividade, com a ampliação da atividade e do trabalho no período noturno até as 22 horas e nos sábados e/ou domingos. Ademais, têm se ampliado as situações em que o trabalho não tem um local específico e se realiza em horário além daquele estabelecido. Dois exemplos podem ser apresentados.

No primeiro, a manutenção de equipamentos nos domicílios ou nas empresas é realizada, muitas vezes, por trabalhadores que não atuam ou não passam pela empresa que os contrata. Na rede de assistência técnica de uma grande empresa de eletrodomésticos, empregados das concessionárias se movem de um para outro cliente sem precisarem passar pela sede da empresa. As peças necessárias para reparar uma máquina de lavar, por exemplo, são requisitadas pelo empregado via rádio e lhe são entregues na casa do cliente por um motoboy. A extensão da jornada desse empregado é determinada pelo número de ordens de serviço que lhe são repassadas para execução em um determinado dia pela empresa. Pode ser que o empregado inicie o atendimento do primeiro cliente às $7 \mathrm{~h} 30$ e a termine somente ao redor das 20 horas, quando a última ordem tiver sido executada. Apesar de seu contrato especificar uma jornada diária de oito horas com os devidos intervalos e compensações, o período efetivamente trabalhado tem dinâmica e intensidade significativamente diferentes.

O outro exemplo a ser explorado é o vivenciado pelos gerentes de agências bancárias. Ao contrário do passado, as agências possuem atualmente diversos gerentes com o objetivo de personalizar o atendimento, apesar de a autonomia de decisão que lhes cabe ter sido substantivamente reduzida. Com o objetivo de evitar possíveis processos trabalhistas, os bancos controlam a jornada em agência de seus funcionários. Porém, como as empresas impõem metas mensais de rendimento aos gerentes, estes levam para casa listas de clientes para serem contatados fora do horário normal de expediente dos bancos. Assim, ao chegarem em casa, os gerentes iniciam as ligações para os clientes a fim de oferecer produtos que lhes permitam cumprir a meta de desempenho mensal. Em geral, o contato é realizado no período 
noturno e, muitas vezes, no final de semana. Portanto, é possível que se perca a dimensão exata da jornada de trabalho, mesmo para os ocupados que têm local específico de trabalho.

Nestas condições de organização da atividade econômica, com o mercado convivendo com um desemprego ponderável e recorrente e com o enfraquecimento do movimento sindical, tornam-se bastante complicadas as mudanças na regulação do contrato trabalho que possam estabelecer limites para a jornada. É possível dar um exemplo dessa dificuldade. Nas condições atuais de integração internacional das economias, uma redução da jornada de trabalho no Brasil para quarenta horas semanais, apesar de inegavelmente justa socialmente, pode alimentar um processo de fuga de produção para a Argentina, onde a regulação da jornada permite ainda 48 horas. Deste modo, uma iniciativa de redução da jornada de trabalho no espaço nacional deve requerer algum procedimento semelhante, ao menos, no âmbito do Mercosul. Em suma, a flexibilidade atual da jornada de trabalho em um contexto de integração internacional das economias apresenta razoável limitação para uma iniciativa de natureza autônoma em favor de sua redução ao nível nacional.

É fundamental apontar que a flexibilidade da jornada não se restringe ao mercado de trabalho, tendendo a ter consequências sobre os demais tempos de atividade que a população adulta exerce. Em primeiro lugar, no que tange ao tempo gasto com transporte. A variabilidade do local de trabalho impede, muitas vezes, que o trabalhador possa estabelecer moradia em região mais fácil para seu acesso e compatível com sua renda. Em segundo lugar, a flexibilidade da jornada rompe sua rotina e seus horários limites, podendo conflitar ou constranger o tempo para as atividades necessárias de reprodução social, isto é, destinado às atividades de organização e administração das responsabilidades da vida individual ou familiar. Ela ainda tende a quebrar a coincidência entre horários de trabalho e de funcionamento dos serviços públicos, como o das creches, criando problemas para as mães com filhos pequenos e que necessitam deste tipo de serviço. Creches públicas em geral funcionam das 7 às 18 horas, regime incompatível com a jornada de trabalho de um ocupado que tem definida a hora de entrada, mas não aquela de saída (Dedecca, 2005; Burda, Hamermesh e Weil, 2006).

Além disso, a flexibilidade acaba permitindo que a jornada de trabalho extrapole o espaço em que ela deveria se realizar, invadindo e constrangendo os tempos associados a outras atividades fundamentais ou necessárias para nossa reprodução social. A situação observada no setor bancário é um exemplo dessa situação. Os gerentes, ao realizarem tarefas no âmbito de seus domicílios, constrangem o tempo destinado para atenção à família ou para realizar atividades de lazer. 
As condições da organização econômica que emergiram com a Segunda Revolução Industrial, que se consolidaram na primeira metade do século $\mathrm{XX}$, não possibilitavam, na maioria das vezes, que o trabalho pudesse ser realizado fora do local específico para sua execução. Assim, a regulação pública, ao reduzir e tornar fixa a jornada no mercado de trabalho, acabou por viabilizar a ampliação do tempo destinado às famílias e ao lazer.

As mudanças recentes na organização econômica, em um contexto de desemprego recorrente e de enfraquecimento sindical, vêm abrindo espaço para a ampliação não visível da jornada de trabalho ou da flexibilidade dos horários em que ela se realiza, invadindo e constrangendo o tempo destinado às demais atividades associadas ao núcleo familiar ou ao lazer (Fisher e Layte, 2002; Dedecca, 2005; Hirata e Kergoat, 2008; Bonke e Gerstoft, 2007).

As transformações na jornada no mercado de trabalho explicitam, deste modo, a interdependência das formas de apropriação do tempo disponível, evidenciando a sua dimensão multifacetada, a qual Norbert Elias (1989) denominou de 'tempos'. A tensão observada entre eles decorre da impossibilidade de modificar sua extensão diária. Isto é, o aumento da extensão de uma das formas de apropriação do tempo diário exige que ao menos uma das demais seja constrangida.

A Segunda Revolução Industrial permitiu, com o advento da energia elétrica, prolongar a atividade produtiva nas fábricas para além da duração do dia. Contudo, ela e todo o desenvolvimento capitalista do século XX não modificaram a extensão do dia, isto é, suas 24 horas. Assim, aumentos da jornada no mercado de trabalho devem ser compensados com reduções da jornada destinada à família ou ao lazer.

Foi a partir desta perspectiva que Norbert Elias considerou a noção de 'tempos' como expressão de uma relação, ao menos, entre dois ou mais processos, necessariamente gerenciada pelo ser humano. De acordo com Elias (1989), a articulação entre os tempos no mercado de trabalho e no núcleo familiar não tem caráter natural, sendo estabelecida segundo normas e regras que regem uma determinada sociedade humana. A articulação atual é distinta daquela consolidada até os anos 70, bem como é diferente daquelas encontradas em sociedades anteriores à capitalista, como a grega, a romana ou a indígena.

A interdependência entre tempos exige da sociedade uma regulação social, independentemente dos objetivos de justiça que ela almeja com este processo. Infelizmente, é escassa a disponibilidade de informação sobre o uso do tempo na sociedade capitalista, sendo recente a existência de levantamentos nacionais. 


\section{A disponibilidade limitada de informação sobre o uso do tempo}

A disponibilidade de informação socioeconômica sobre a apropriação do tempo disponível pela sociedade brasileira é bastante restrita. A Pesquisa Nacional por Amostra de Domicílios (Pnad), única fonte disponível, explora e disponibiliza uma informação agregada sobre as horas destinadas pela população para o trabalho, a locomoção entre a moradia e o trabalho e os afazeres domésticos.

A Pnad levanta informação sobre a quantidade de horas segundo estas três formas de uso do tempo, sem realizar uma qualificação sobre os tipos de atividades incorporadas a cada uma delas. Os indicadores são exclusivamente quantitativos, não sendo possível saber o que está se medindo. Mesmo restrita, a Pnad se constitui em uma das únicas fontes com alguma informação sobre o uso do tempo extramercado de trabalho dentre os países em desenvolvimento. As pesquisas sistemáticas destinadas à mensuração sobre o uso de tempo são realizadas somente por países da Europa Ocidental, dos Estados Unidos e do Canadá. 6

Mesmo reconhecendo esta limitação que caracteriza a base de dados, é inegável que seus resultados permitem alguma avaliação sobre a apropriação do tempo na sociedade brasileira. Ao menos uma primeira aproximação do processo, mesmo que de modo bastante agregado. Uma evidência deste argumento encontra-se sintetizada no Gráfico 1, que consolida o dado nacional de modo compatível ao organizado por outros países, mesmo que estes tenham um levantamento mais detalhado sobre o uso do tempo.

Nesta compatibilização, que expressa a conduta que será adotada ao longo deste ensaio, considera-se o tempo associado aos afazeres domésticos, segundo o Instituto Brasileiro de Geografia e Estatística (IBGE), como sendo destinado à reprodução social. Pois se entende que as atividades realizadas no âmbito dos domicílios são fundamentais não somente para a reprodução das famílias, mas também para a sociedade como um todo. É inegável que os cuidados das famílias com seus filhos na alimentação, nos hábitos de higiene e no acesso à cultura têm grande relevância para a inserção deles no sistema de educação e mesmo no mercado de trabalho. A reprodução econômica e social requer uma boa administração das atividades tanto no espaço das empresas quanto naquele das famílias. 
Gráfico 1

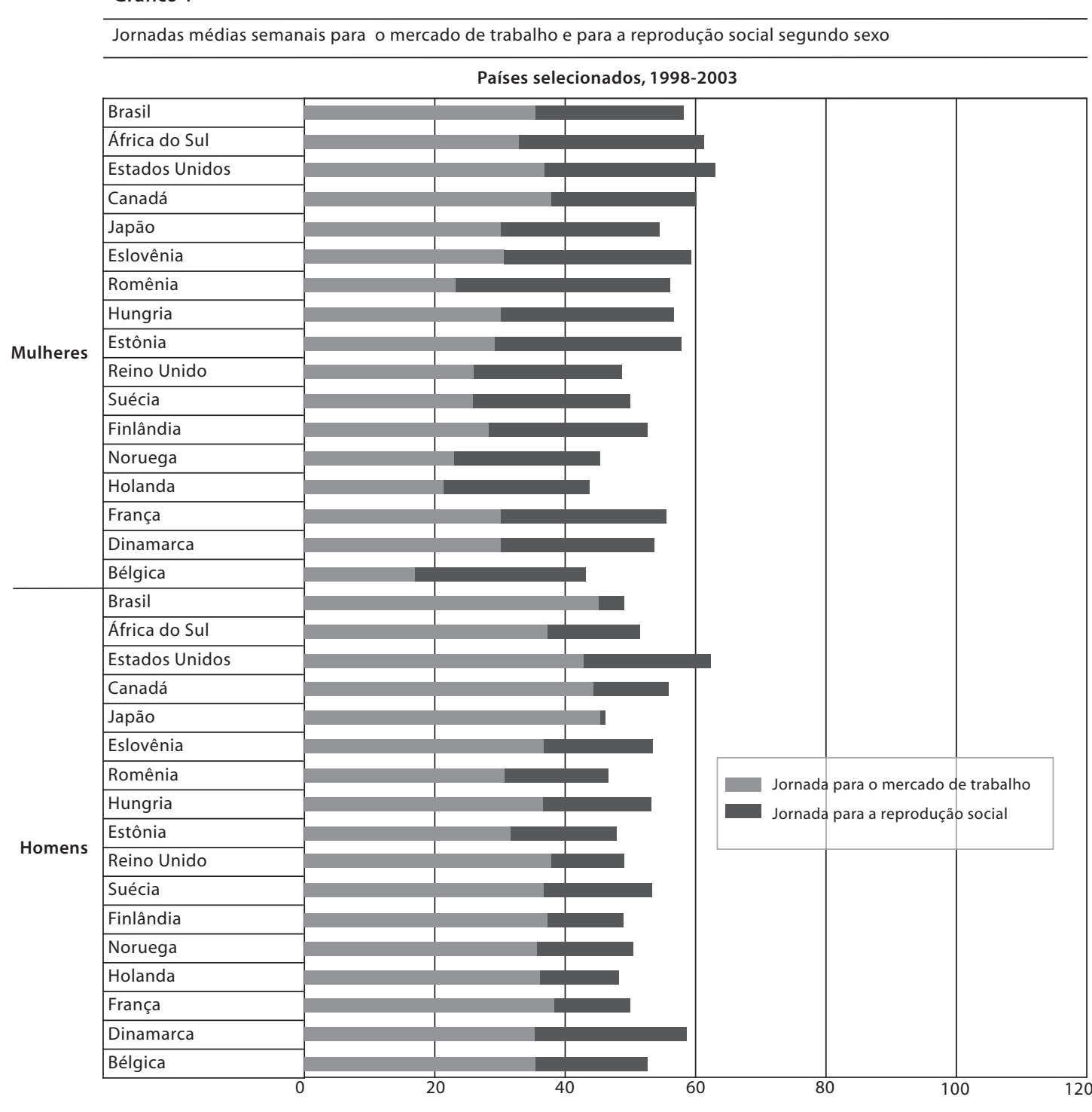

Fonte: IBGE, Pesquisa Nacional por Amostra de Domicílios, Pnad-IBGE, 2002, Rio de Janeiro; Statistics Bureau, Survey on Time Use and Leisure Activities, 2003 Luxembourg; BLS, Time Use Survey, 2003; Statistics Canada, Overview of Time Use of Cadadians in 1998, s/d .

Apresentado o procedimento metodológico básico adotado no ensaio, é possível conhecer o resultado agregado do uso do tempo informado pela Pnad e compará-lo aos divulgados por outros países (Gráfico 1).

A primeira dimensão que salta aos olhos na comparação é a elevada jornada total de trabalho realizada pela população brasileira, em especial pelas mulheres. Os dados não chancelam uma visão bastante difundida sobre uma suposta baixa intensidade do trabalho no país. Eles mostram que 
a intensidade do trabalho ocorre tanto no mercado como no âmbito dos domicílios. Para as mulheres, a jornada total de trabalho quase alcança sessenta horas semanais, sendo que este resultado médio guarda, como se verá mais adiante, uma ponderável heterogeneidade de situações.

A partir da construção da matriz analítica que justifica os estudos sobre o uso do tempo, abre-se a possibilidade de se explorar a preocupação central deste ensaio: a existência de um contexto socioeconômico marcado por uma forte discriminação das mulheres tanto no mercado de trabalho como em suas famílias, a elevada intensidade das jornadas de trabalho e a maior precariedade da situação ocupacional, desvantagens que se encontram relacionadas entre si.

\section{Os tempos de trabalho na sociedade brasileira}

O desenvolvimento da análise será realizado considerando duas dimensões básicas da atividade do trabalho. A primeira será aquela associada ao status ocupacional derivado da hierarquia das ocupações, conduta em geral adotada nos estudos sobre estrutura e mobilidade social. A outra será vinculada ao gasto de tempo com jornadas realizadas pela população no mercado de trabalho e nos domicílios. A primeira dimensão sinaliza a posição social derivada da inserção no mercado de trabalho e a segunda indica o grau de apropriação do tempo disponível da população pelos processos de reprodução econômica e social. Esta perspectiva metodológica foi inicialmente adotada em Dedecca (2008).

Os resultados gerais mostram que, em 2006, homens e mulheres na condição de ocupados tinham jornadas totais de trabalho de 49 horas e 56 horas, respectivamente. Contudo, a composição da jornada total era significativamente distinta entre sexos. Os homens tinham uma jornada de trabalho média equivalente à jornada constitucional de 44 horas e destinavam cinco para a reprodução social. As mulheres exerciam jornadas de 37 horas no mercado de trabalho e 19 horas para a reprodução social, resultando em uma jornada de trabalho total em média 15\% superior à dos homens. Esta diferenciação do nível e da composição da jornada de trabalho total entre homens e mulheres ganha novos matizes quando considerados alguns enfoques complementares relativos ao nível de renda, à posição na família ou à raça/cor.

Considerando a situação de 'renda de todos os trabalhos' dos ocupados, nota-se a tendência de redução da participação da jornada de trabalho destinada à reprodução social dos homens. Este efeito não decorre da redução absoluta desta jornada para níveis mais elevados de renda: ela se mantém estável e reduzida em termos absolutos, mas a jornada de trabalho 
no mercado tende a aumentar, de modo que a participação da reprodução social na composição da jornada total tende a se reduzir.

Situação distinta é encontrada para as mulheres: a elevação do nível de renda é acompanhada por redução substancial da jornada de trabalho destinada à reprodução social e por elevação da jornada de mercado, o que resulta em tendência de elevação da jornada total com mudança do caráter de sua composição. Assim, nota-se que a mulher de renda mais elevada tem a opção de priorizar a jornada do mercado, buscando uma inserção de melhor qualidade, melhores oportunidades, cargos mais elevados e remunerações mais altas. No entanto, é muito provável que ela só tenha condições de fazer isso se conseguir se desembaraçar de parte ou do conjunto dos seus afazeres domésticos, devendo conseguir esta situação, principalmente, pela contratação de uma trabalhadora doméstica para se responsabilizar ao menos por parte das atividades do domicílio. ${ }^{7}$

A mulher de renda mais baixa, porém, não conta com esta possibilidade de reduzir o tempo despendido na reprodução social, tendo no máximo o auxílio de filhos ou de outros familiares para fazê-lo, conhecendo uma situação de maior constrangimento na conciliação desta jornada com aquela realizada no mercado de trabalho. São justamente as mulheres de menor renda aquelas que têm maior fração do seu tempo apropriada pela atividade em seus próprios domicílios. A discriminação do tempo de trabalho pode ser rapidamente visualizada nos resultados compilados no Gráfico 2.

\section{Gráfico 2}

Composição da jornada de trabalho total dos ocupados por sexo e classe de salário mínimo (SM) - Brasil, 2006

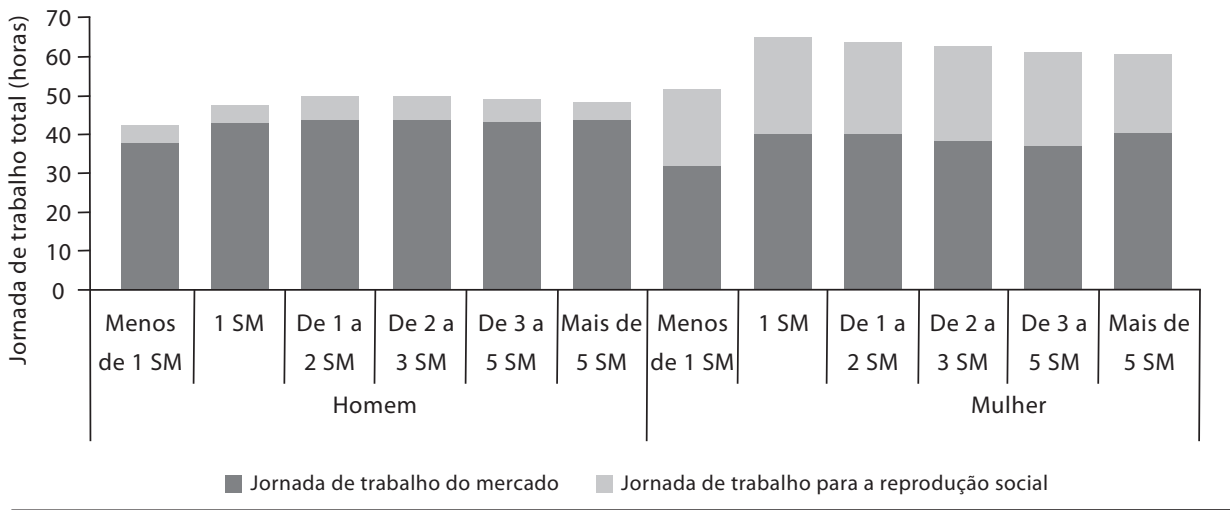

Fonte: Pnad, 2006

A jornada dos ocupados por escolaridade e grupos ocupacionais, como será visto mais adiante, revela que, no caso das mulheres, estas dimensões são tão relevantes para compreender a dinâmica de formação e composição da jornada de trabalho quanto à observada para a renda. 
As mais elevadas jornadas para a reprodução social são exercidas pelas mulheres com menor escolaridade. Porém, as mais escolarizadas e que exercem ocupações com maior prestígio social (como as dirigentes e as profissionais das ciências e das artes) tendem a ter uma melhor inserção no mercado e um menor exercício nas atividades domiciliares, em razão de haver uma alta probabilidade de delegarem as atividades domésticas aos trabalhadores remunerados.

Parece haver, portanto, uma relação inversa entre nível de escolaridade e jornada de trabalho (Gráfico 3) destinada à reprodução social: mulheres com baixa escolaridade costumam ter jornadas domésticas em média 75\% superiores às das mulheres com nível superior completo. No que tange aos homens, essa situação é praticamente inexistente: o tempo destinado aos afazeres domésticos se reduz com o aumento da escolaridade, mas a diferença de apropriação do tempo com esta destinação entre as escolaridades baixas e as mais elevadas corresponde somente a 10\%. Há, portanto, uma situação bastante estável da jornada para a reprodução social dos homens quando considerada a escala de escolaridade.

A jornada de trabalho para o mercado, contudo, costuma apresentar um comportamento errático tanto para homens quanto para mulheres (embora com tendência de elevação para estas). As jornadas médias femininas são sempre menores do que as masculinas, o que deve ser reflexo de alguma limitação da inserção feminina no mercado de trabalho, resultante do extenso trabalho no âmbito das famílias. A amplamente reconhecida responsabilidade do cuidado da casa e dos filhos dificulta a realização de uma carga horária de trabalho mais elevada no mercado quanto àquela que os homens podem manter. No entanto, a jornada total feminina é sempre superior à masculina.

Gráfico 3

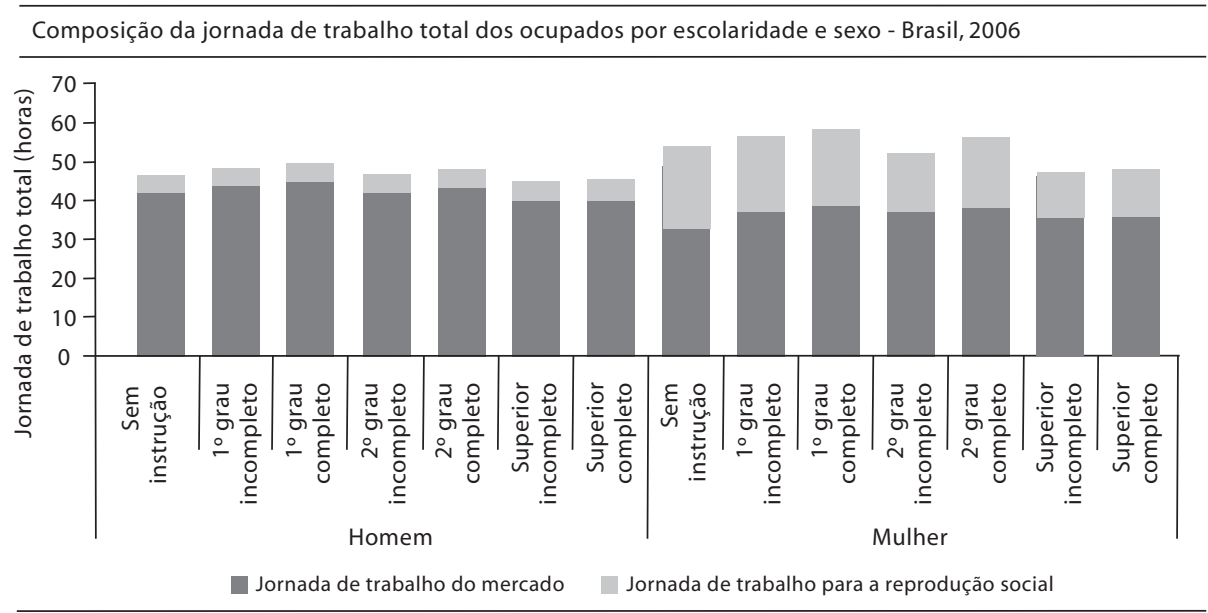

Fonte: Pnad, 2006 
Os homens de escolaridade mais elevada são caracterizados por jornadas totais mais longas, por conta da elevação progressiva daquela. Quanto ao tempo destinado para a reprodução social, praticamente independe do nível de escolaridade e renda. As mulheres, porém, tendem a ter jornadas totais declinantes à medida que possuam escolaridade mais alta, pois, apesar da elevação das horas trabalhadas no âmbito do mercado, o tempo destinado à reprodução social se reduz conforme se eleva o nível de escolaridade. De tal modo que a jornada total é mais elevada para mulheres de escolaridade mais baixa e a participação do período destinado às tarefas domésticas é maior no conjunto das horas de trabalho destas.

\section{Gráfico 4}

Composição da jornada de trabalho total dos ocupados por tipo de família e sexo Brasil, 2006

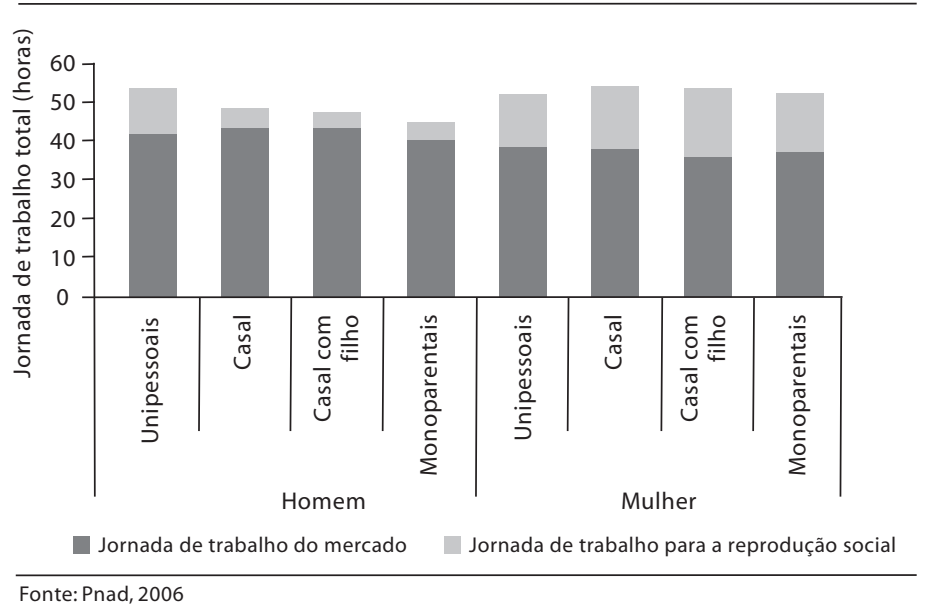

\section{As famílias e os tempos de trabalho}

Uma perspectiva muito relevante para a análise da jornada de trabalho é aquela associada ao tipo de família (Gráfico 4), em razão de a extensão das atividades de reprodução social se diferenciar segundo a composição do núcleo familiar. Neste ensaio, se adota a classificação de famílias definida pela Pnad.

As famílias unipessoais são caracterizadas por jornadas de trabalho totais praticamente iguais, sendo que a jornada masculina destinada à reprodução social é um pouco inferior à feminina. Ou seja, os resultados sugerem que o homem que mora sozinho tem menor probabilidade de não executar ele mesmo as tarefas do lar.

Contudo, quando se consideram os ocupados pertencentes à composição familiar de casal com ou sem filhos, a situação se altera substanti- 
vamente. Nesse caso, a jornada masculina relativa aos cuidados da casa se reduz bastante e a da mulher se eleva de maneira intensiva.

Observa-se que a mulher, em uma situação familiar com um maior número de membros, tende invariavelmente a se tornar responsável pelas atividades domésticas. Já o homem deixa de realizar as tarefas que executava quando solteiro (ou reduz o tempo que despende fazendo-as). O tipo de família parece não se constituir em fator de diferenciação da jornada de trabalho de mercado, mas é bastante significativo para analisar a disposição da incumbência doméstica entre os sexos, de modo que possui forte influência sobre a composição da jornada total.

Na família, as mulheres tradicionalmente se ocupam dos afazeres domésticos, o que limita sobremaneira o tempo que podem dedicar ao mercado de trabalho e impõe um grande esforço de conciliação das jornadas, que tende a reiterar uma situação de desvantagem da inserção feminina no mercado de trabalho.

A posição na família aponta que esta também é uma condição que praticamente pouco diferencia o padrão de jornada no mercado de trabalho: as jornadas concernentes à reprodução social novamente se mantêm constantes entre os homens e as maiores cargas horárias entre as mulheres são referentes às cônjuges, em primeiro lugar, e às chefes de família, em segundo (Gráfico 5). Estas últimas, por sua vez, desempenham muito mais tarefas domésticas do que os homens na mesma condição. Situação semelhante é encontrada para os descendentes: as filhas tendem a se responsabilizar pela reprodução social desde cedo, muito mais do que os filhos.

Gráfico 5

Composição da jornada de trabalho total dos ocupados por posição na família e sexo - Brasil, 2006

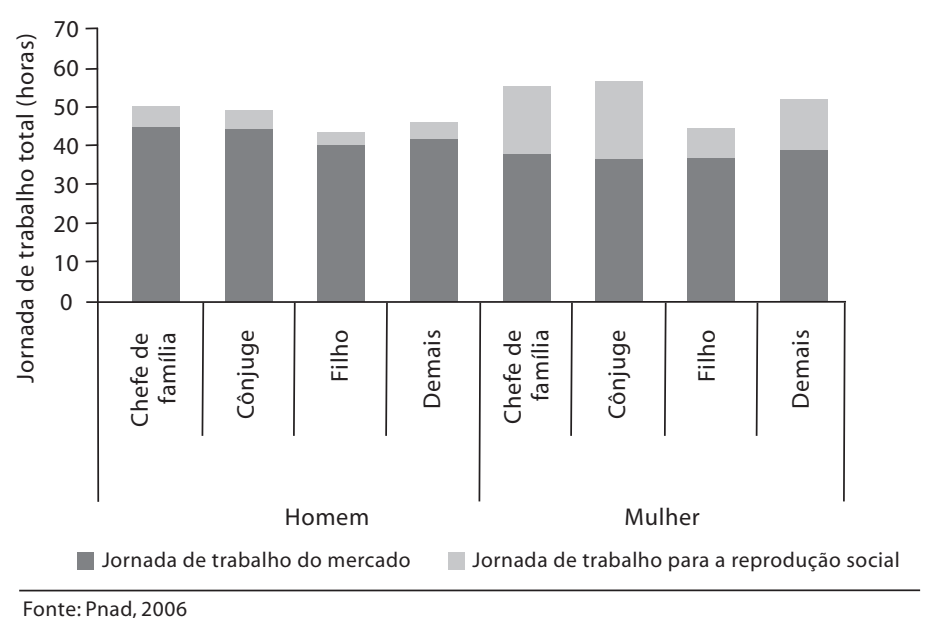


O Gráfico 6 particulariza a questão da jornada de trabalho para os filhos em duas regiões geográficas do país mais populosas e contrastantes economicamente: o Sudeste e o Nordeste. Evidencia-se mais uma vez que os fatores sexo e renda são fortes diferenciadores da jornada total. Novamente, a jornada destinada à reprodução social se mantém praticamente inalterada para os homens, independentemente do nível de renda ou da região considerada, e, portanto, do grau de desenvolvimento econômico. Quanto às filhas, por sua vez, a jornada no mercado de trabalho é mais alta no Sudeste, o que reflete as maiores oportunidades de inserção econômica no mercado desta região. Mostra-se, porém, que as filhas tendem a se ocupar mais das tarefas domésticas quando provêm de famílias de renda mais baixa. Em primeiro lugar, porque as pessoas oriundas de faixas de renda mais elevadas permanecem mais tempo nos bancos escolares e em outras atividades recreativas e educacionais, tendo, portanto, menor disponibilidade para auxiliar em casa; e, em segundo lugar, porque famílias de renda mais elevada podem contratar empregados remunerados para realizar o trabalho doméstico, de modo que o auxílio dos filhos é pouco demandado.

\section{Gráfico 6}

Composição da jornada de trabalho total dos filhos ocupados por sexo e classe de salário mínimo (SM) Brasil, 2006

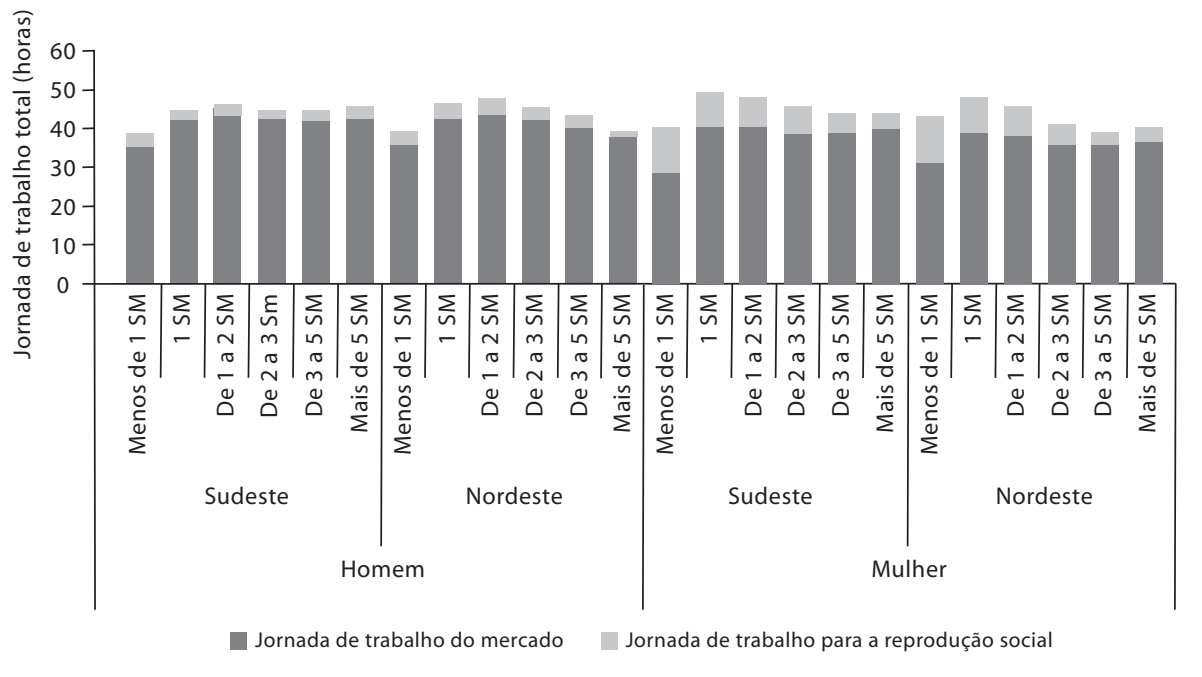

Fonte: Pnad, 2006

As diferenças regionais quanto ao montante absoluto de horas destinadas ao trabalho em casa são pouco expressivas: a questão mais marcante 
é o peso delas na jornada total, que é reduzido na região Sudeste por conta de as jornadas no mercado serem, em geral, mais elevadas.

A situação de raça/cor dos ocupados não revela uma nova dimensão da discriminação entre homens e mulheres quanto ao nível e à composição da jornada de trabalho total (Gráfico 7), mas sanciona a diferença entre homens e mulheres anteriormente apresentada: nota-se que as mulheres pretas e pardas têm jornada de trabalho total superior às das demais e que as mais elevadas jornadas dedicadas à reprodução social estão concentradas nas indígenas, nas pretas e nas pardas. Quanto aos homens, a cor oferece pouca diferenciação; nota-se apenas que os pretos e indígenas têm as maiores jornadas dedicadas à reprodução social e que os pretos e brancos têm as maiores jornadas totais, mas as diferenças são muito pequenas.

Gráfico 7

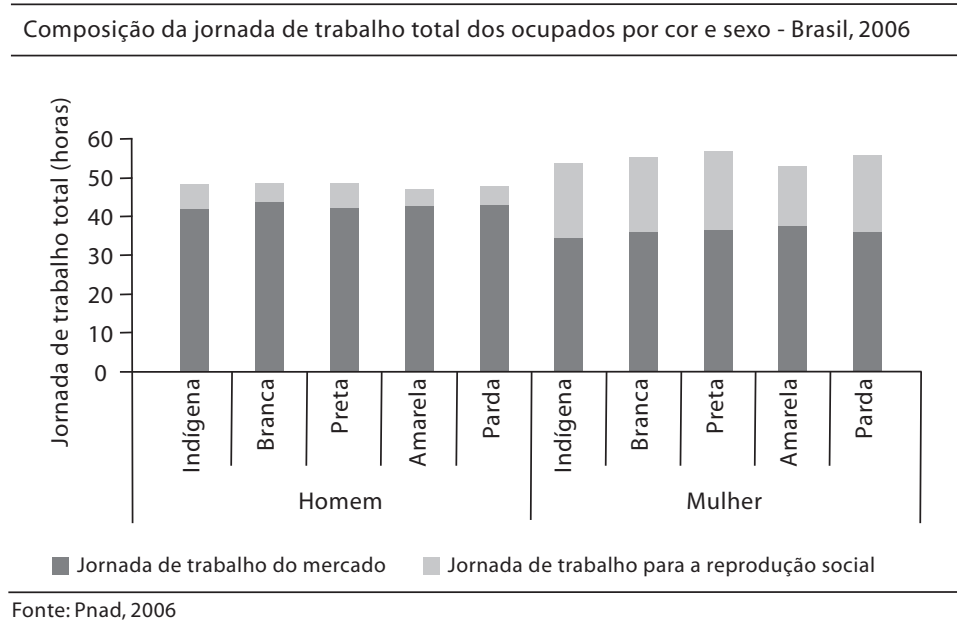

O enfoque conjunto de posição na família e classes de renda familiar por salário mínimo (Tabela 1) permite observar que as mulheres chefes de família têm uma carga de responsabilidades sobre a reprodução social que é inversamente proporcional à renda. Essas mulheres devem ter menor probabilidade de realizar uma inserção de qualidade no mercado: estão demasiadamente comprometidas com a atividade de reprodução social, terminando por terem menor disponibilidade de tempo para o mercado de trabalho. Embora as mais elevadas jornadas totais estejam concentradas nas ocupadas que auferem rendimentos ente dois e três salários mínimos, o tempo apropriado para a reprodução social é mais de $100 \%$ superior para as mulheres com rendimento inferior a um salário mínimo com relação às de renda mais alta (Tabela 1). 
Tabela 1

\begin{tabular}{|c|c|c|c|c|c|c|c|c|c|}
\hline \multicolumn{10}{|c|}{ Jornadas de trabalho do mercado e total por sexo e classes de salário mínimo (SM) - Brasil, 2006} \\
\hline \multirow{2}{*}{ Sexo } & \multirow{2}{*}{\multicolumn{2}{|c|}{ Posição na família }} & \multicolumn{7}{|c|}{ Classes de salário mínimo } \\
\hline & & & $\begin{array}{c}\text { Menos de } \\
1 \mathrm{SM}\end{array}$ & $1 \mathrm{SM}$ & $\begin{array}{l}\text { Acima de } \\
1 \text { até } 2 \text { SM }\end{array}$ & $\begin{array}{l}\text { Acima de } \\
2 \text { até } 3 \mathrm{SM}\end{array}$ & $\begin{array}{l}\text { Acima de } \\
3 \text { até } 5 \text { SM }\end{array}$ & $\begin{array}{c}\text { Acima de } \\
5 \mathrm{SM}\end{array}$ & Total \\
\hline \multirow{10}{*}{ 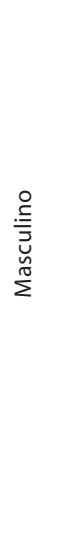 } & Chefe de & JTm & 39,51 & 45,42 & 46,18 & 46,71 & 46,33 & 45,63 & 45,04 \\
\hline & família & $\mathrm{JTt}$ & 45,67 & 50,65 & 51,89 & 52,20 & 51,55 & 49,94 & 50,47 \\
\hline & Cônjuge & $\mathrm{JTm}$ & 39,48 & 45,87 & 45,78 & 46,05 & 45,86 & 45,51 & 44,86 \\
\hline & & $\mathrm{JTt}$ & 45,10 & 50,60 & 50,82 & 50,76 & 49,61 & 48,77 & 49,56 \\
\hline & Filho & $\mathrm{JTm}$ & 34,89 & 43,02 & 43,79 & 43,51 & 42,75 & 43,07 & 41,07 \\
\hline & & $\mathrm{JTt}$ & 38,81 & 45,91 & 46,61 & 45,91 & 45,22 & 45,06 & 44,12 \\
\hline & Demais & $\mathrm{JTm}$ & 36,78 & 43,92 & 44,36 & 45,03 & 43,38 & 46,10 & 42,40 \\
\hline & & $\mathrm{JTt}$ & 41,60 & 48,22 & 48,93 & 50,49 & 48,21 & 49,22 & 47,04 \\
\hline & Total & JTm & 37,85 & 44,60 & 45,49 & 46,12 & 45,76 & 45,43 & 44,02 \\
\hline & & $\mathrm{JTt}$ & 43,18 & 49,01 & 50,40 & 51,07 & 50,53 & 49,49 & 48,85 \\
\hline \multirow{10}{*}{ 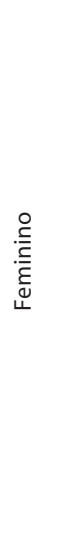 } & Chefe de & $\mathrm{JTm}$ & 29,67 & 41,37 & 41,80 & 41,07 & 39,72 & 41,20 & 38,27 \\
\hline & família & $\mathrm{JTt}$ & 53,56 & 59,63 & 59,77 & 57,98 & 55,41 & 52,88 & 57,06 \\
\hline & Cônjuge & JTm & 26,72 & 39,25 & 40,04 & 39,80 & 38,73 & 40,83 & 36,31 \\
\hline & & $\mathrm{JTt}$ & 55,67 & 61,91 & 62,09 & 59,47 & 57,21 & 54,63 & 59,14 \\
\hline & Filho & $\mathrm{JTm}$ & 29,84 & 40,69 & 40,89 & 39,32 & 39,37 & 40,53 & 37,55 \\
\hline & & $\mathrm{JTt}$ & 42,68 & 50,39 & 49,45 & 46,52 & 46,00 & 45,61 & 47,17 \\
\hline & Demais & $\mathrm{JTm}$ & 34,40 & 43,38 & 42,32 & 42,00 & 39,64 & 40,29 & 39,93 \\
\hline & & $\mathrm{JTt}$ & 51,58 & 56,86 & 55,35 & 54,21 & 49,87 & 48,52 & 54,00 \\
\hline & Total & $\mathrm{JTm}$ & 28,62 & 40,44 & 40,84 & 40,15 & 39,16 & 40,92 & 37,30 \\
\hline & & $\mathrm{JTt}$ & 52,27 & 58,43 & 58,51 & 56,44 & 54,71 & 52,97 & 55,98 \\
\hline
\end{tabular}

Fonte: Pnad, 2006

\section{Status ocupacional e os tempos de trabalho}

A análise realizada até o presente momento sinaliza que as condições socioeconômicas das mulheres tendem a estar relacionadas a uma inserção mais desfavorável no mercado de trabalho, em termos de jornada. Considerando tal percurso analítico, faz-se necessário explorar a relação entre status ocupacional, renda e jornada de trabalho. Esta perspectiva tem grande relevância, pois é esperado que as discrepâncias de jornadas totais entre homens e mulheres tendam a cair para as situações ocupacionais com status e renda mais elevados. Os resultados apresentados na Tabela 2 confirmam parcialmente esta tese. 
Quando analisadas as diferenças de jornada para reprodução social, nota-se que o maior status ocupacional encontra-se associado a uma menor jornada deste tipo, sendo, no entanto, ligado a um maior tempo despendido no mercado de trabalho (Tabela 2). É interessante observar que a maior participação da mulher no mercado de trabalho e a sua melhor inserção ocupacional se relacionam a uma jornada para reprodução social ponderável, mesmo que esta seja inferior à observada para as mulheres com status ocupacional e renda mais baixa.

Os resultados revelam que a melhor inserção ocupacional ameniza a discriminação em relação à mulher, mas não permite superar sua situação de desvantagem em termos de jornada de trabalho para reprodução social, seja porque elas continuam a realizar um volume ponderável de horas com este objetivo, seja porque os homens em mesma situação não ampliam suas responsabilidades nas atividades de reprodução social da família.

Tabela 2

Horas semanais trabalhadas no mercado de trabalho (JTm) e na reprodução social (JTrs) segundo categorias ocupacionais, sexo e classes de salário mínimo - Brasil, 2006

\begin{tabular}{|c|c|c|c|c|c|c|c|c|c|c|c|c|}
\hline & \multicolumn{6}{|c|}{ Masculino } & \multicolumn{6}{|c|}{ Feminino } \\
\hline & $\begin{array}{l}\text { Menos } \\
\text { de } 1 \mathrm{SM}\end{array}$ & $1 \mathrm{SM}$ & $\begin{array}{l}\text { De } 1 \text { a } \\
2 \mathrm{SM}\end{array}$ & $\begin{array}{c}\text { De } 2 \text { a } \\
3 \mathrm{SM}\end{array}$ & $\begin{array}{c}\text { De } 3 \text { a } \\
5 \mathrm{SM}\end{array}$ & $\begin{array}{c}\text { Mais de } \\
5 \mathrm{SM}\end{array}$ & $\begin{array}{l}\text { Menos } \\
\text { de } 1 \mathrm{SM}\end{array}$ & $1 \mathrm{SM}$ & $\begin{array}{c}\text { De } 1 \text { a } \\
2 \mathrm{SM}\end{array}$ & $\begin{array}{c}\text { De } 2 \text { a } \\
3 \mathrm{SM}\end{array}$ & $\begin{array}{c}\text { De } 3 \text { a } \\
5 \mathrm{SM}\end{array}$ & $\begin{array}{c}\text { Mais de } \\
5 \mathrm{SM}\end{array}$ \\
\hline & \multicolumn{12}{|c|}{ Jornada de trabalho total } \\
\hline Dirigentes em geral & 49,43 & 49,99 & 51,77 & 52,23 & 52,33 & 51,43 & 57,76 & 59,11 & 60,22 & 59,83 & 57,46 & 55,80 \\
\hline $\begin{array}{l}\text { Profissionais das } \\
\text { ciências e das artes }\end{array}$ & 30,67 & 39,63 & 40,54 & 42,94 & 44,03 & 45,61 & 44,66 & 46,41 & 48,04 & 48,64 & 50,04 & 49,86 \\
\hline $\begin{array}{l}\text { Técnico de nível } \\
\text { médio }\end{array}$ & 31,46 & 42,38 & 44,70 & 46,42 & 46,82 & 47,30 & 41,08 & 51,82 & 54,12 & 55,24 & 55,08 & 52,46 \\
\hline $\begin{array}{l}\text { Trabalhadores de } \\
\text { serviços } \\
\text { administrativos }\end{array}$ & 35,14 & 43,69 & 47,26 & 47,48 & 47,41 & 46,30 & 43,60 & 53,54 & 55,58 & 55,15 & 54,67 & 51,86 \\
\hline $\begin{array}{l}\text { Trabalhadores dos } \\
\text { serviços }\end{array}$ & 41,59 & 50,16 & 52,32 & 54,82 & 53,22 & 51,41 & 52,82 & 60,72 & 61,59 & 62,32 & 63,66 & 61,14 \\
\hline $\begin{array}{l}\text { Vendedores e } \\
\text { prestadores de } \\
\text { serviço do comércio }\end{array}$ & 43,17 & 51,27 & 52,07 & 52,94 & 52,39 & 52,42 & 53,37 & 58,91 & 60,05 & 60,24 & 60,54 & 60,28 \\
\hline $\begin{array}{l}\text { Trabalhadores } \\
\text { agrícolas }\end{array}$ & 44,43 & 50,81 & 52,20 & 53,99 & 53,46 & 51,32 & 56,05 & 61,73 & 61,74 & 62,33 & 59,18 & 49,34 \\
\hline $\begin{array}{l}\text { Trabalhadores da } \\
\text { produção de B/S e } \\
\text { de reparação e } \\
\text { manutenção }\end{array}$ & 43,84 & 48,79 & 50,41 & 51,70 & 52,31 & 53,73 & 53,29 & 59,98 & 61,90 & 62,42 & 60,82 & 60,02 \\
\hline $\begin{array}{l}\text { Membros das forças } \\
\text { armadas e auxiliares }\end{array}$ & 49,18 & 47,82 & 48,00 & 47,66 & 50,51 & 49,12 & 40,00 & - & 69,72 & 52,87 & 63,63 & 54,64 \\
\hline Total & 43,18 & 49,01 & 50,40 & 51,07 & 50,53 & 49,49 & 52,27 & 58,43 & 58,51 & 56,44 & 54,71 & 52,97 \\
\hline
\end{tabular}


Continuação - Tabela 2

\begin{tabular}{|c|c|c|c|c|c|c|c|c|c|c|c|c|}
\hline & \multicolumn{6}{|c|}{ Masculino } & \multicolumn{6}{|c|}{ Feminino } \\
\hline & $\begin{array}{l}\text { Menos } \\
\text { de } 1 \mathrm{SM}\end{array}$ & $1 \mathrm{SM}$ & $\begin{array}{l}\text { De } 1 \text { a } \\
2 \text { SM }\end{array}$ & $\begin{array}{c}\text { De } 2 \text { a } \\
3 \mathrm{SM}\end{array}$ & $\begin{array}{c}\text { De } 3 a \\
5 \mathrm{SM}\end{array}$ & $\begin{array}{c}\text { Mais de } \\
5 \mathrm{SM}\end{array}$ & $\begin{array}{l}\text { Menos } \\
\text { de } 1 \mathrm{SM}\end{array}$ & $1 \mathrm{SM}$ & $\begin{array}{l}\text { De } 1 \text { a } \\
2 \mathrm{SM}\end{array}$ & $\begin{array}{c}\text { De } 2 \text { a } \\
3 \mathrm{SM}\end{array}$ & $\begin{array}{c}\text { De } 3 \text { a } \\
5 \mathrm{SM}\end{array}$ & $\begin{array}{c}\text { Mais de } \\
5 \mathrm{SM}\end{array}$ \\
\hline & \multicolumn{12}{|c|}{ Jornada de trabalho total dedicada à reprodução social } \\
\hline Dirigentes em geral & 4,17 & 4,83 & 3,74 & 3,71 & 3,86 & 3,03 & 16,22 & 16,80 & 14,85 & 15,05 & 14,45 & 11,43 \\
\hline $\begin{array}{l}\text { Profissionais das } \\
\text { ciências e das artes }\end{array}$ & 4,86 & 6,72 & 5,67 & 5,28 & 5,02 & 4,18 & 22,48 & 16,41 & 17,43 & 15,47 & 14,70 & 11,19 \\
\hline $\begin{array}{l}\text { Técnico de nível } \\
\text { médio }\end{array}$ & 5,96 & 5,31 & 4,99 & 4,99 & 4,97 & 4,83 & 20,70 & 19,08 & 18,46 & 17,73 & 16,99 & 12,80 \\
\hline $\begin{array}{l}\text { Trabalhadores de } \\
\text { serviços } \\
\text { administrativos }\end{array}$ & 4,02 & 3,67 & 4,51 & 5,24 & 5,24 & 4,94 & 14,04 & 13,75 & 14,15 & 14,30 & 14,69 & 12,98 \\
\hline $\begin{array}{l}\text { Trabalhadores dos } \\
\text { serviços }\end{array}$ & 6,21 & 5,09 & 6,44 & 6,85 & 5,90 & 5,51 & 23,05 & 19,49 & 19,79 & 18,54 & 18,84 & 14,14 \\
\hline $\begin{array}{l}\text { Vendedores e } \\
\text { prestadores de } \\
\text { serviço do comércio }\end{array}$ & 5,45 & 4,53 & 4,92 & 4,91 & 4,52 & 4,52 & 25,65 & 15,53 & 16,58 & 16,95 & 16,00 & 15,40 \\
\hline $\begin{array}{l}\text { Trabalhadores } \\
\text { agrícolas }\end{array}$ & 5,28 & 4,14 & 4,07 & 4,20 & 4,12 & 2,78 & 25,81 & 19,00 & 20,01 & 21,68 & 22,86 & 18,51 \\
\hline $\begin{array}{l}\text { Trabalhadores da } \\
\text { produção de B/S e } \\
\text { de reparação e } \\
\text { manutenção }\end{array}$ & 5,12 & 4,02 & 4,67 & 4,76 & 4,56 & 4,26 & 26,13 & 17,96 & 18,85 & 17,74 & 16,48 & 16,45 \\
\hline $\begin{array}{l}\text { Membros das forças } \\
\text { armadas e auxiliares }\end{array}$ & 3,29 & 2,64 & 3,74 & 4,46 & 6,26 & 5,92 & 0,00 & - & 17,12 & 9,56 & 20,91 & 13,68 \\
\hline \multirow[t]{2}{*}{ Total } & 5,33 & 4,41 & 4,91 & 4,96 & 4,77 & 4,06 & 23,66 & 17,99 & 17,67 & 16,30 & 15,55 & 12,05 \\
\hline & \multicolumn{12}{|c|}{ Jornada de trabalho total dedicada à reprodução social } \\
\hline Dirigentes em geral & 45,26 & 45,16 & 48,03 & 48,52 & 48,47 & 48,40 & 41,54 & 42,31 & 45,37 & 44,77 & 43,01 & 44,37 \\
\hline $\begin{array}{l}\text { Profissionais das } \\
\text { ciências e das artes }\end{array}$ & 25,81 & 32,91 & 34,86 & 37,67 & 39,01 & 41,43 & 22,18 & 30,01 & 30,61 & 33,17 & 35,34 & 38,68 \\
\hline $\begin{array}{l}\text { Técnico de nível } \\
\text { médio }\end{array}$ & 25,50 & 37,07 & 39,71 & 41,44 & 41,85 & 42,47 & 20,38 & 32,74 & 35,66 & 37,51 & 38,09 & 39,66 \\
\hline $\begin{array}{l}\text { Trabalhadores de } \\
\text { serviços } \\
\text { administrativos }\end{array}$ & 31,12 & 40,02 & 42,76 & 42,25 & 42,17 & 41,36 & 29,56 & 39,79 & 41,43 & 40,85 & 39,97 & 38,88 \\
\hline $\begin{array}{l}\text { Trabalhadores dos } \\
\text { serviços }\end{array}$ & 35,38 & 45,07 & 45,88 & 47,97 & 47,33 & 45,90 & 29,78 & 41,24 & 41,80 & 43,77 & 44,82 & 47,00 \\
\hline $\begin{array}{l}\text { Vendedores e } \\
\text { prestadores de } \\
\text { serviço do comércio }\end{array}$ & 37,72 & 46,73 & 47,15 & 48,03 & 47,87 & 47,90 & 27,72 & 43,37 & 43,47 & 43,29 & 44,54 & 44,88 \\
\hline $\begin{array}{l}\text { Trabalhadores } \\
\text { agrícolas }\end{array}$ & 39,14 & 46,67 & 48,12 & 49,80 & 49,34 & 48,54 & 30,24 & 42,73 & 41,72 & 40,66 & 36,32 & 30,82 \\
\hline $\begin{array}{l}\text { Trabalhadores da } \\
\text { produção de } B / S \text { e } \\
\text { de reparação e } \\
\text { manutenção }\end{array}$ & 38,72 & 44,78 & 45,74 & 46,94 & 47,76 & 49,48 & 27,16 & 42,02 & 43,06 & 44,68 & 44,34 & 43,57 \\
\hline $\begin{array}{l}\text { Membros das forças } \\
\text { armadas e auxiliares }\end{array}$ & 45,89 & 45,18 & 44,26 & 43,20 & 44,25 & 43,20 & 40,00 & - & 52,61 & 43,31 & 42,73 & 40,95 \\
\hline Total & 37,85 & 44,60 & 45,49 & 46,12 & 45,76 & 45,43 & 28,65 & 40,44 & 40,84 & 40,15 & 39,16 & 40,92 \\
\hline
\end{tabular}


Quando analisada a situação das mulheres com status ocupacional e renda mais baixa, constata-se uma clara situação de desvantagem destas em relação aos homens em situação semelhante, bem como em comparação às mulheres em situação mais favorável em termos de inserção ocupacional e renda.

Em suma, a Pnad revela que quanto mais desfavoráveis a inserção ocupacional e a renda, maior é a jornada de trabalho da mulher. Em outras palavras, quanto menor a probabilidade de ela ter acesso a uma ocupação com proteção social, maior é sua responsabilidade no âmbito familiar. Estes resultados expressam condições desfavoráveis para a mulher tanto no mercado de trabalho como no âmbito da família, os quais devem estar relacionados.

Uma síntese dos argumentos expostos anteriormente é apresentada no Gráfico 8. De maneira geral, nota-se que os homens são bastante homogêneos em relação ao tempo despendido na execução de tarefas concernentes à reprodução social: sempre têm menos de dez horas do seu tempo destinado a elas. A diferenciação (caracterizada, ademais, por pequena dispersão) está relacionada, sobretudo, à jornada no mercado, que alcança o ápice para os homens dirigentes (maior qualificação e maior prestígio social, portanto), para os envolvidos com o comércio e para os trabalhadores da produção (menores qualificação e prestígio), e tem os menores valores para os profissionais das ciências e das artes.

No que tange às mulheres, porém, a dispersão é bidirecional: elas são caracterizadas, no geral, por jornadas elevadas tanto no ambiente doméstico quanto no mercado de trabalho, com possibilidades de combinações. Elas, por sua vez, sempre têm mais do que dez horas do seu tempo ocupado pela reprodução social e suas jornadas no mercado são pouco inferiores às dos homens. As mulheres envolvidas com o trabalho agrícola e com os serviços são as que apresentam as maiores combinações de jornadas elevadas em ambas as direções; as dirigentes têm as maiores jornadas no mercado e as menores de reprodução social, enquanto as trabalhadoras agrícolas, as maiores de reprodução social e as menores no mercado.

Essas evidências sugerem que as mulheres menos qualificadas e alocadas em ocupações menos prestigiadas socialmente têm jornadas totais maiores do que as mais qualificadas e alocadas em ocupações mais estáveis e prestigiadas. Embora estas últimas apresentem significativa elevação da jornada no mercado em relação às primeiras, não é suficiente para compensar a diferença na jornada doméstica, de modo que as menos qualificadas acabam por ter jornadas totais mais elevadas. 
das ao setor de serviços, nos segmentos de serviços administrativos e das profissões de ciências e artes, o que aponta que o emprego feminino cresce em qualidade e demanda por qualificação, mas é caracterizado por um declínio mais acentuado de remunerações, comparativamente àquele que acomete os homens.

Nota-se que as mulheres estão mais qualificadas e se inserindo mais no mercado de trabalho, mas auferindo remunerações piores para essas ocupações. E, portanto, que um maior dinamismo do mercado de trabalho não parece ser suficiente para atenuar a jornada de trabalho total das mulheres.

De modo geral, o crescimento do emprego para as mulheres está acontecendo justamente naquelas ocupações em que ela se realiza mais das tarefas domésticas (por conta do nível de renda, principalmente) e precisa, ao mesmo tempo, dedicar um número de horas elevado ao mercado de trabalho. Portanto, a dinâmica ocupacional está legitimando uma situação de elevada jornada total de trabalho para as mulheres, que precisam se virar para conciliar o trabalho fora de casa com o de dentro de casa e arquitetar tudo com a baixa renda de que dispõe. Tal fato demonstra que pouca atenção tem sido conferida a esse aspecto da inserção ocupacional feminina: a inexistência de instrumentos legais para se lidar com o duplo trabalho das mulheres faz com que elas tenham que se esgotar numa dupla jornada bastante intensa, que tende a se elevar por conta dos pequenos ganhos reais de renda e da necessidade de buscar uma inserção no mercado de maior qualidade, que demanda mais horas de dedicação (Bonke e Gerstoft, 2007).

\section{Considerações finais}

A Pnad revela que, de maneira geral, as mulheres são penalizadas por sua condição de provedoras da reprodução social do lar através de jornadas de trabalho totais mais longas, tendo que conciliar a necessidade de desempenhar as tarefas domésticas com a inserção no mercado de trabalho. O resultado global explicita que elas trabalham em média 18 horas semanais a mais do que os homens.

Ademais, a Pnad deixa claro que, quanto mais desfavorável for a inserção ocupacional da mulher e quanto mais baixa a sua renda, maior é a distância entre a jornada de trabalho a que ela está submetida, comparativamente àquela exercida pelos homens na mesma condição. Além disso, quanto pior a qualidade da ocupação que ela realiza, maior é a sua jornada total de trabalho e maior a participação do trabalho em casa na apropriação do seu tempo. Assim sendo, menor é o tempo que ela pode dedicar ao trabalho fora de casa, o que aponta na direção de uma inserção de pior qualidade no mercado. 
O nível mais baixo de escolaridade também está relacionado à jornada de trabalho total maior e com maior participação nela das horas dedicadas à reprodução social, e essa situação se agrava para as mulheres chefes de família. No entanto, é preciso também observar que essa tendência começa antes mesmo de a mulher constituir família: ainda na posição de filha ela já sente o peso desses deveres, especialmente quando é oriunda de família de baixa renda em um contexto no qual ela não só se responsabiliza pelas tarefas domésticas, mas também muitas vezes pela criação dos próprios irmãos, enquanto a mãe está no mercado de trabalho).

Em uma perspectiva mais ampla, os resultados deste ensaio sinalizam para a necessidade de políticas públicas de proteção ao trabalho que extrapolem a dimensão do mercado de trabalho, alcançando as atividades complementares que a população ativa realiza no interior das famílias. Estas políticas são particularmente relevantes para as mulheres e, em especial, para aquelas com menor qualificação e renda, pois são elas que se encontram em posição mais desvantajosa tanto no mercado de trabalho como nas famílias (Adam, 1990; Hirata e Kergoat, 2008).

Ao contrário da perspectiva de menor regulação pública do mercado de trabalho, muitas vezes defendida sob a justificativa de maior liberdade das partes no processo de contratação, verifica-se a necessidade de ampliação desta regulação, pois ela se constitui em elemento relevante para o enfrentamento da desigualdade entre homens e mulheres no mercado de trabalho e no núcleo familiar.

Se deixada a regulação aos resultados das dinâmicas dos mercados de bens, serviços e trabalho, será pouco provável que venha se construir uma situação de maior igualdade entre homens e mulheres no mercado de trabalho, mas também no âmbito das famílias, ao menos no que disser respeito à extensão e composição da jornada de trabalho total.

\section{Notas}

1 Professor Titular do Instituto de Economia da Universidade Estadual de Campinas (Unicamp), Campinas, São Paulo, Brasil. Doutor em Ciência Econômica pela Unicamp. <claudio.dedecca@eco.unicamp.br>

Correspondência: Instituto de Economia da Universidade Estadual de Campinas (Unicamp), Caixa Postal 6135, Campinas, São Paulo, Brasil, CEP 13083-970.

2 Auxiliar de pesquisa do Centro de Estudos Sindicais e de Economia do Trabalho, do Instituto de Economia, da Universidade Estadual de Campinas (Cesit/IE/Unicamp). Graduanda em Ciências Econômicas pela Unicamp. <camila.freitas.ribeiro@gmail.com> 
3 Auxiliar de pesquisa do Centro de Estudos Sindicais e de Economia do Trabalho, do Instituto de Economia, da Universidade Estadual de Campinas (Cesit/IE/Unicamp). Graduando em Ciências Econômicas pela Unicamp. < fernando.hajime@gmail.com>

4 Desde meados da década de 1940, duas reivindicações começaram a ser feitas pelos trabalhadores aos seus Estados, tanto na Europa como na América do Norte, para regulação pública do contrato de trabalho: a redução da jornada de trabalho para oito horas e o estabelecimento de um salário mínimo. Em conjunto, elas visavam a proteger o salário real, ao buscarem impedir a sua desvalorização absoluta por meio da redução do salário nominal hora e dele, em termos relativos, através da ampliação não remunerada da jornada de trabalho.

5 Um bom exemplo disso é a experiência francesa. Nos anos 80, o país reduziu a jornada semanal de trabalho para quarenta horas e, na segunda metade da década de 1990, para 36 horas. Recentemente, o governo francês flexibilizou a regulação com o objetivo de viabilizar jornadas superiores a 36 horas sem custo adicional. A iniciativa foi justificada pela perda de emprego nas unidades produtivas locais, em razão de empresas francesas estarem deslocando produção para os países do leste europeu, onde a regulação da jornada de trabalho é mais flexível ou ausente.

6 Sobre os levantamentos nacionais sobre o uso do tempo, ver Fisher e Layte (2002); e Dedecca (2005).

7 A Pnad, infelizmente, não realiza o levantamento sobre a existência de contratação de empregado doméstico no domicílio. Assim, o argumento de uma menor jornada para reprodução social das mulheres ocupadas de renda mais elevada decorre do conhecimento comum que se tem da generalização deste tipo de trabalho nos domicílios de renda média e alta no Brasil.

\section{Referências}

ADAM, Barbara. Time and Social Theory. Oxford: Polity Press, 1990.

BONKE, Jens; GERSTOFT, Frederik. Stress, time use and gender. Electronic International Journal of Time Use Research, v. 4, n. 1, p. $47-68,2007$.

BURDA, Michael C.; HAMERMESH, Daniel S.; WEIL, Philippe. The Distribution of Total Work in the EU and US. Discussion Paper Series, n. 2.270. Bonn: IZA, 2006.

DEDECCA, Claudio Salvadori. Sobre tempos e gênero na sociedade brasileira. In: DEDECCA, Claudio Salvadori. Trabalho e gênero no Brasil: formas, tempo e contribuições sócioeconômicas. Brasília: Unifem, 2005.

Regimes de trabalho, uso do tempo e desigualdade entre homens e mulheres. In: COSTA, A. de O.; SORJ, B.; BRUSCHINI, C.; HIRATA, H.. Mercado de trabalho e gênero: comparações internacionais. Rio de Janeiro: FGV Editora, 2008.

ELIAS, Norbert. Sobre el Tiempo. México, D. F.: Fondo de Cultura Económica, 1989.

FISHER, Kimberly; LAYTE, Richard. Measuring Work-Life Balance and Degrees of Sociability: a focus on the value of time use 
data in the assessment of quality of life, EAPG Working Paper, n. 32. Colchester: University of Essex, 2002.

HIRATA, H.; KERGOAT, D. Divisão sexual do trabalho profissional e doméstico: Brasil, França e Japão. In: COSTA, A. de O.; SORJ, B.; BRUSCHINI, C.; HIRATA, H.. Mercado de trabalho e gênero: comparações internacionais. Rio de Janeiro: FGV Editora, 2008.
SCHOR, Juliet. The Overworked American: the unexpected decline of leisure. New York: Basic Books, 1991.

THOMPSON, Edward Palmer. Time, workdiscipline, and industrial capitalism, Past and Present, n. 38, p. 56-97, 1967.

Recebido em 10/07/2008

Aprovado em 25/02/2009 